\title{
The Impact of Isolation Measures during COVID-19 Pandemic on Russian Students' Motivation for Learning
}

\author{
Albina R. Drozdikova-Zaripova ${ }^{1}$, Roza A. Valeeva ${ }^{1, *}$ and Niyaz R. Latypov ${ }^{2}$ \\ 1 Institute of Psychology and Education, Kazan Federal University, 420008 Kazan, Russia; bina1976@rambler.ru \\ 2 Institute of International Relations, Kazan Federal University, 42000 Kazan, Russia; inyazlat@yandex.ru \\ * Correspondence: valeykin@yandex.ru; Tel.: +7-906-113-71-20
}

check for

updates

Citation: Drozdikova-Zaripova, A.R.; Valeeva, R.A.; Latypov, N.R. The Impact of Isolation Measures during COVID-19 Pandemic on Russian Students' Motivation for Learning. Educ. Sci. 2021, 11, 722. https:// doi.org/10.3390/educsci11110722

Academic Editors: Riccardo Pecori, Pietro Ducange, Paolo Raviolo and Pietro Picerno

Received: 25 September 2021 Accepted: 8 November 2021 Published: 11 November 2021

Publisher's Note: MDPI stays neutral with regard to jurisdictional claims in published maps and institutional affiliations.

Copyright: (c) 2021 by the authors. Licensee MDPI, Basel, Switzerland. This article is an open access article distributed under the terms and conditions of the Creative Commons Attribution (CC BY) license (https:/ / creativecommons.org/licenses/by/ $4.0 /)$.

\begin{abstract}
One of the leading problems of teaching is maintaining the students' motivation for learning. In the current epidemiological situation, improvement of education quality using digital platforms and educational services by creating conditions for increasing the learning motivation of students is an essential and relevant task. Therefore, the aim of the research was to study the motivation of the educational activity of junior students during the COVID-19 lockdown period and the development of effective approaches to increase the learning motivation of students in the context of distance learning using the Microsoft Teams platform. Research methods: Theoretical analysis of psychological and pedagogical literature, generalization; experiment, questioning, testing and data processing methods. In total, 107 undergraduates took part in the study. The difficulties and benefits that students encountered during the lockdown, as well as the attitude of students to the distance learning format, were revealed. There were specified dominant motivators, intentions and motives that determine the educational activity of students. We have presented approaches to the content management of the educational process in a distance format, with various ways and techniques of increasing the educational motivation of students under the conditions of distance learning.
\end{abstract}

Keywords: motivation; motivation for learning; students; distance learning; Flipped Classroom; Microsoft Teams

\section{Introduction}

\subsection{Relevance of the Problem}

Under modern conditions, society demands high standards of the higher professional education system in the training of highly qualified, competitive specialists. One of the key problems of the educational process is the motivation of students' learning activities. It has acquired particular importance in connection with the current epidemiological situation and with the forced and urgent transition of higher educational institutions to distance learning [1-5].

In March 2020, force majeure circumstances made most Russian universities fundamentally restructure the educational process, moving towards reliance on the level of their IT infrastructure system development, based on the availability of electronic educational resources and the digital proficiency of teachers and students to use software, online platforms and services in the educational process. Taking into account the IT infrastructure, Russian universities have developed various scenarios for students' training in an online environment and corresponding requirements for the given formats of the educational process.

The COVID-19 pandemic is a crisis that has exposed the reality and expectations of today, as well as opening up new challenges and prospects for us in the field of education in the coming years. Many teachers and students agree that the most difficult thing in distance learning is to stay motivated [6-10].

The effectiveness of the teacher's ability to activate the audience decreases significantly during teaching using distance learning technologies. There emerged many objective and 
subjective difficulties in the educational process associated with the transformation of the educational and methodological complex for the needs of a distance format, along with requirements for technical equipment and the personal difficulties of students under conditions of social distancing. Among these are the habits of systematic teacher supervision and control, weak self-organization, the initially low intrinsic motivation of students, insufficient skills of independent work (which is especially typical for junior students), as well as the limited ability to interact with other students and teachers [11-14].

The problems involved in the transition to distance learning include teaching staff's reluctance to change their common practice, most often due to the so-called resistance to change and a significantly increased load on the teacher [15].

In this regard, the problem of creating optimal conditions for increasing motivation for educational activities and professional development at student age, in the context of a new educational paradigm, with the use of distance learning technologies is increasingly gaining special relevance and urgency.

\subsection{The Extent of Prior Study on the Problem}

The problem of motivation in general and motivation for educational activity in particular is one of the fundamental problems of Russian and international psychology [16]

Regarding the available research focused on investigating the motivations of students' educational activities, then in recent years it is worth mentioning a number of the following interesting studies. There is a number of works addressing motives for entering a university $[17,18]$. In his works, M.G. Rogov (1998) came to the conclusion that the main motives of the educational activity of students are the motives of personality development and achieving success [19]. According to F.M. Rakhmatulina (1981) and S.E. Chirkina (2013) and others, the educational activity of students is mainly characterized by three types of motives: professional, cognitive, and the motive for achieving success [20,21].

A number of works on psychology and pedagogy address the specificity and dynamics of changes in the hierarchy of motives for learning among university students of different specialties and ages, as well as taking into account their secondary employment [22-24].

The research of V.A. Tenkov (2015) identified the structural components of motivation: pleasure from the activity itself, the significance of the immediate result, and reward for the activity; it is also shown that the development of educational motivation is an integral part of a student's personality formation [25].

In recent years, international and Russian researchers have been actively involved in studying distance learning motivation: J. Keller [26], N.V. Sokolskaya [27], A.S. Afanasyeva [28], B.N. Morat, A. Shaari and M.J.Z. Abidin [29], M.Y. Melor, H. Salehi, \& C. Chenzi [30], H.-C.K. Hsu, C.V. Wang, C. Levesque-Bristol [31], E. Johnson, R. Morwane, S. Dada, G. Pretorius, M. Lotriet [32], M.E.O. Luna, C.S.L. Cruz, J.O. Arce [33] and others.

Russian scientists are investigating changes in the educational motivation of students during the pandemic, how it influenced (or will affect in the future) the success of their professional education, and how it can become an important aspect in choosing a profession. The research performed by N.A. Grigoryan, T.S. Kolmakova and L.K. Galustyan (2020) showed that the epidemiological situation in the country did not affect the choice of the future profession of a doctor or the refusal to make such a choice despite the increased risks associated with that profession [34]. The motivation of the first-year students in the context of distance learning is associated with common life values, personal meanings of life, and future profession [4]. Students that had previous experience of using distance learning technologies demonstrate a greater desire to acquire knowledge and master the profession. In total, $86.4 \%$ of respondents are confident that they have enough willpower to learn without any reminders or encouragement [35].

The data obtained by V.N. Panferov, S.A. Bezgodov and A.V. Miklyaeva (2020) indicate a reduction in the educational motivation of students, and this trend continues as the experience of distance learning expands, despite the increase in involvement in the educational process; professional motivation in general remains fairly stable [36]. In the 
context of forced distance learning during the COVID-19 pandemic, the level of student motivation is much lower on average than that of students with an independent choice of distance learning, even before the onset of the pandemic [37].

The factors influencing the motivation of students under the conditions of online education during the pandemic have been identified: external (organization of the process and structure of the course) and internal (personal parameters (orientation, interests, personal growth, progress satisfaction, personality of a teacher and the relationship that he or she has with students, etc.)) $[5,38]$. Both categories of the factors can have positive as well as negative effects on motivation. It is shown that intrinsic motivation is the main component in distance and blended learning, and plays a more important role in motivating students than extrinsic motivation. Timelines and realistic goals are central to the intrinsic motivation of online students. It is necessary for teachers to provide timely and high-quality feedback to motivate students. Difficulties in organizing effective intensive communication between students and teachers are a common disadvantage that negatively affects student motivation [5].

A significant number of respondents noted that after the transition to a distance learning format, both the complexity of the training and the amount of time they spent on study increased. The factors with a high positive influence on educational motivation, according to students, include the possibility of acquiring new knowledge and skills, awareness of the importance of education for success in the future and material incentives, and factors with a high negative influence include the lack of time and a suitable environment for study [5]. Most respondents believe that their motivation decreased [5,38].

In foreign literature, much attention is paid to exactly what changes are introduced to the organization under the distance learning format, how they influence the motivational component of learning, and what difficulties students faced for this reason. In addition to the expected negative trends, it was found that students with high levels of self-confidence during the transition to online learning mediated by digital technologies have no difficulties with social interaction and in sustaining high motivation, which they lacked in the context of the traditional offline format of education [39].

As a result of the restrictions imposed, the research participants developed feelings of insecurity and isolation, loss of meaning, and decreased self-esteem and motivation [40].

M. Dickey (2004), J. Owens, L. Hardcastle and Richardson (2009) showed that learning motivation is negatively affected by feelings of isolation [41,42].

According to the materials of O. Lovrich, N. Farcic, S. Miksic and others (2020), the crisis caused by COVID-19 has led to a decrease in attention and learning motivation, as well as memory impairments. The authors emphasize that this is a common phenomenon among medical students during periods of epidemics, which subsequently has a negative impact on their academic performance [43].

The ARCS (Attention, Relevance, Confidence and Satisfaction) model of increasing students' motivation, created by John Keller, deserves special attention [26,44,45].

It is known that the effectiveness of the online education of students largely depends on their skills in interacting with the digital educational environment [46]. Research results have shown that online learning during the COVID-19 pandemic impeded the personalizing of students and prevented them from making decisions about their educational activities on the internet [47].

Of particular interest are studies aimed at identifying psychological and pedagogical factors, and developing methods and techniques that facilitate a significant increase in students' motivation to learn using distance learning technologies. Among these factors, the authors name the following: the presence of their own learning strategy [48]; organization and self-discipline $[48,49]$; the opportunity to interact with other participants in distance learning and provide students with regular and timely feedback, including feedback on the possibilities of practical application of the knowledge gained and the development of ways of self-development and self-improvement [48,50,51]; the use of interactive forms of teaching and innovative teaching technologies [51-55]; assisting students in realizing 
their own goals and tapping potential, creating opportunities for achieving success, maintaining and increasing students' self-esteem within the available time and resources [51]; changing the interests and needs of students through the transformation of awareness and understanding of their educational activities [11].

\section{Materials and Methods}

\subsection{Purpose of the Research}

The purpose of this research is to study junior students' motivation for learning during the lockdown period and the development of effective approaches to increase the motivation of the students' educational activity in the context of distance learning using the Microsoft Teams platform (KFU case study).

\subsection{Research Base of the Study}

The research was conducted at the Kazan (Volga Region) Federal University. In total, there were 107 students (2nd and 3rd year undergraduates of the bachelor's program) from the Institute of Psychology and Education, Institute of Physics, and the Institute of Fundamental Medicine and Biology that took part in the experiment. Most of them, 47.6\% of the students, study at the Institute of Psychology and Education. The majority of the test subjects were female ( $84.3 \%$ of the total number). The study was conducted at the end of April 2020.

\subsection{Research Methods and Techniques}

We used a complex of mutually complementary methods to undertake the research: experiment, questioning, testing and data processing methods.

The study used diagnostic tools aided by the online Google forms:

(1) A uniquely designed questionnaire that consists of 15 questions - this is aimed at studying the attitude of students to the distance format of classes, identifying difficulties and positive aspects that they encountered during the lockdown, as well as performing a self-assessment of their physical and mental health;

(2) A methodology for diagnosing the students' motivation for learning (A.A. Rean and V.A. Yakunin modified by N.C. Badmaeva), revealing the motives of educational activity (communicative, professional, educational and cognitive, broad social motives, as well as the motives of creative self-realization, avoiding failure and pursuing prestige). In this questionnaire, each statement that reflects the motives of educational activity must be rated on a scale of 1 to 5 . In accordance with the represented significance for the subject, 1 point corresponds to the minimum significance of the motive, 5 points-to the maximum significance;

(3) "Motivation for Success and Fear of Failure" methodology (A.A. Rean's questionnaire), consisting of 20 questions. For each answer matching the answer key, the subject is awarded one point, and motivation for failure or motivation for success is diagnosed based on the total number of points scored;

(4) Diagnostics of the motivators of the socio-psychological activity of an individual, which determines the leading needs-motivators of the individual, in accordance with the expression of his or her consent or disagreement according to a five-point system for each statement from the perspective of the distance learning implementation;

(5) "Circles of Relationships" projective methodology (a modified version of the methodology by T.V. Rumyantseva), which characterizes students' personal attitude to distance learning, both at the present time and as the desired attitude. The respondent needs to place two circles within the space at the most attractive positions relative to each other. One of the circles characterizes the personality of the respondent, and the other the process of distance learning;

(6) Method of semantic differential, structuring the perception of students of the evaluated concepts (objects) according to 6 factors - the activity of the object, its intensity (potency), evaluation (the attitude of the respondent towards it), the orderliness and 
complexity of the object, and the comfort of the object's implementation. Every test subject is offered a list of 18 paired adjectives expressing qualitatively opposite characteristics of the assessed concept, on a scale that determines the degree of this particular characteristic's manifestation of the proposed concept ( 0 stands for the characteristic not being expressed; -1 or 1 -poorly expressed; -2 or 2 -moderately expressed; -3 or 3-strongly expressed). The subjects were asked to rate five concepts.

\section{Results}

\subsection{Findings of the Research}

On the basis of the study, we investigated the problems of organizing the educational process in a distance format, which can affect changes in the students' educational motivation. It is essential to consider the results of some questions of the questionnaire (Table 1).

According to $42.2 \%$ of the respondents, distance learning can only partially replace full-time education. As for the question "Is it more convenient for you to study in a distance learning environment?" most of the answers were "no, it is more inconvenient" - $35.8 \%$ —and "yes, a little more convenient" $-32.1 \%$ - which indicates the ambiguity of students' opinions on this issue.

The positive aspects of the distance learning format include, first of all, location independence (85\%), comfortable conditions during classes $(50.4 \%)$, and the rational distribution of working time (43.9\%). As for the difficulties, they indicted heavy workload $(74.8 \%)$ and technical problems in the organization of the educational process $(61.7 \%)$. It is important to note that in fact, half of the students had difficulties in the self-organization of educational activities-41.1\%; $24.3 \%$ had difficulties in receiving feedback from the teacher.

Most of the subjects rated their state of physical and mental health during the period of distance learning as neutral (34.9\%) and good (33.9\%), and 8.3\% considered their state of health unsatisfactory, and only $6.4 \%$ stated that they feel wonderful.

More than $40 \%$ of the respondents assumed that distance learning will negatively affect the quality of student education; $44 \%$ of the test subjects expressed an opinion that the results will remain the same as under traditional (offline) education.

The subjects rated the effectiveness of the traditional (offline) format of education on a 10-point scale; 7.64 points was the average value for the group. When distributed by points, in terms of intensity, the respondents rated it at the level of 7,8 and 9 points, respectively. Under the conditions of distance learning, the effectiveness in a group was 6.1 points out of the 10-points maximum. The distributions of points changed, and 5, 6, 7, and 8 point ratings were given by the students.

As for the question "Would you like to continue to study in the distance format?", $43.1 \%$ of the students answered "no", $34.9 \%$ of the respondents doubted their choice, and only $22 \%$ of the total number of subjects gave an affirmative answer.

Among the solutions to improve the organization of distance learning, there were various options proposed for the effective organization of the educational process and the search for alternative platforms and learning technologies. Interesting responses included: enhance verbal interaction; reduce the number of reporting tasks; organize physical drills; use interactive online whiteboards/platforms to discuss theory and practice; use a single information platform; use a hybrid training format, such that when lecture material is studied remotely, seminars and practical classes are held in a traditional offline format.

It was found that under the conditions of the distance format of the educational process, students have new goals, intentions, inclinations and motives that determine their educational activity. Among these, according to the degree of importance, students mentioned communicative motives, professional motives and motives of creative selfrealization. The least significant educational motive (occupying the last place in the hierarchy of motives) for students was the motive of avoiding failure (Table 1). 
Table 1. The diagnostic results of students' learning motivation.

\begin{tabular}{lc}
\hline \multicolumn{1}{c}{ Motive Types } & Points \\
\hline Communicative motives & $3.85 \pm 0.76$ \\
Avoidance motives & $2.60 \pm 0.96$ \\
Prestige motives & $3.12 \pm 1.0$ \\
Professional motives & $3.76 \pm 0.95$ \\
Personal potential empowerment motives & $3.75 \pm 0.97$ \\
Learning and cognitive motives & $3.64 \pm 0.82$ \\
Social motives & $3.44 \pm 0.79$ \\
\hline
\end{tabular}

Students' activity is based on the hope for success and the need to achieve success (Figure 1).

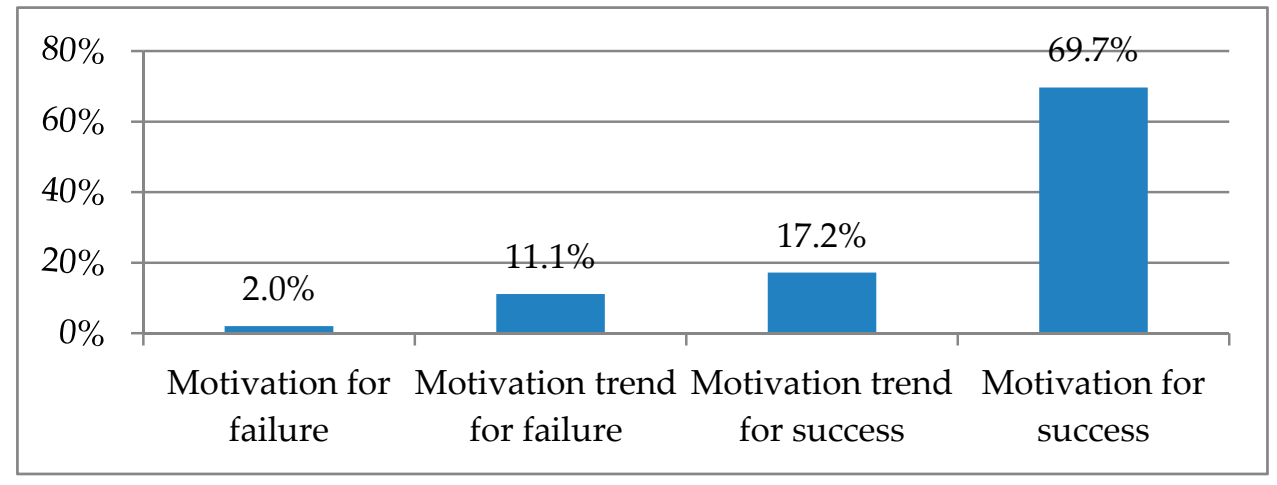

Figure 1. Results according to the "Motivation for Success and Fear of Failure" methodology (questionnaire developed by A.A. Rean).

It has been identified that by creating conditions for achieving success and expressing group respect in the educational process of a distance format, it is possible to increase the subject-activity motivation of students (Table 2).

Table 2. Diagnostics results of the motivators of students' social and psychological activity.

\begin{tabular}{lc}
\hline \multicolumn{1}{c}{ Motivators of Social and Psychological Activity } & Points \\
\hline Achieving success in general & $19.87 \pm 3.11$ \\
Striving for power and recognition & $16.68 \pm 3.38$ \\
Affiliation tendency (group respect) & $18.54 \pm 2.88$ \\
\hline
\end{tabular}

The data obtained after conducting the projective drawing test (Table 3) allow us to state that the subjective feeling of "inclusion" in the educational process in a distance format was observed in $17 \%$ of cases. "Distancing" and cooperation were observed among $41.5 \%$ of the students, respectively.

From the standpoint of the desired relationship, the number of students willing to "cooperate" rose to $49.2 \%$. Therefore, we can say that students have an understanding of distance learning, and they perceive it as significant (Table 3).

Table 3. Results of the "Circles of Relationships" methodology applied.

\begin{tabular}{lcc}
\hline \multicolumn{1}{c}{ Attitude to Distance Learning } & Real Attitude (\%) & Desired Attitude (\%) \\
\hline Symbiosis (inclusion) & $16.9 \%$ & $12.3 \%$ \\
Cooperation & $41.5 \%$ & $49.2 \%$ \\
Distancing & $41.5 \%$ & $32.3 \%$ \\
\hline
\end{tabular}

Following the study of the subjective perception of distance learning in students using the method of semantic differential (Table 4), it was found that in the "Evaluation" 
factor category, students had indicators below the average value as regards the emotional perception of their own studies, achievement of success, and the manifestation of their hobbies. The perception of distance learning and of the implementation of their learning duties within the framework of this training format was found to be very low. This indicates a critical attitude of students towards themselves, dissatisfaction with their own behavior, level of achievements and personality traits, and insufficient levels of self-acceptance in extreme situations.

As for the "Activity" and "Potency" factors, the results obtained are within the lower range. These indicators demonstrate passivity and calm emotional reactions, lack of selfcontrol, inability to adhere to the accepted behavior pattern, and dependence on external circumstances and marks they get during the period of online learning.

According to the analysis of "Orderliness", "Complexity" and "Comfort" factors, the subjects had difficulties in assessing the degree of the factors' exposure and personal significance in a new learning scenario.

Table 4. Results of the study of students' perception using the method of semantic differential.

\begin{tabular}{lcccccc}
\hline \multicolumn{1}{c}{ Concepts/Factors } & Evaluation & Activity & Potency & Complexity & Ordering & Comfort \\
\hline 1. My studies & 1.53 & 1.26 & 1.15 & 0.56 & 0.33 & 0.66 \\
2. Distance learning & 0.4 & 0.69 & 0.69 & 0.21 & -0.18 & 0.13 \\
3. Success achievement & 1.83 & 1.31 & 1.35 & 1.12 & 0.22 & 0.33 \\
4. My hobby & 1.88 & 1.3 & 1 & 1 & 0.22 & 0.96 \\
5. My duties & 0.55 & 0.9 & 0.61 & 0.15 & 0.42 & 0.5 \\
\hline
\end{tabular}

Based on the results obtained by the method of semantic differential, strong, direct, highly significant correlations were revealed, in terms of characteristics, between students perception of distance learning activity and personal attitude to the new learning format $(\mathrm{r}=0.89, p \leq 0.01)$, as well as the level of personal energy and efforts applied to it $(r=0.86$, $p \leq 0.01)$, between the applied efforts and the difficulties in distance learning $(r=0.85$, $p \leq 0.01)$.

\subsection{Approaches and Techniques for Increasing the Educational Motivation of Students in the Context of Distance Learning}

The organization of activities (forms, methods, techniques) and the content of the educational process (selection of the content for knowledge acquisition, structural organization and presentation of the educational material) play important roles in the organization of distance learning and in maintaining the motivation of the students.

In the context of the pandemic at the Kazan Federal University, the educational process was carried out in a distance format with the support of the IT Department of the University, using the Microsoft Teams platform for online classes and consultations, uploading content, testing students' knowledge, and organizing communication between students and teachers in combination with the use of other services for online learning, such as social networks and e-mail.

In our opinion, blended learning technology was enhanced by the most effective model of Flipped Classroom, which involves the obligatory conducting of online lessons as part of the curriculum in the format of videoconferencing by means of the Microsoft Teams platform; this is a very promising way of organizing the educational activity of students in a distance format (Figure 2). 


\section{Teaching activities}

Student activities

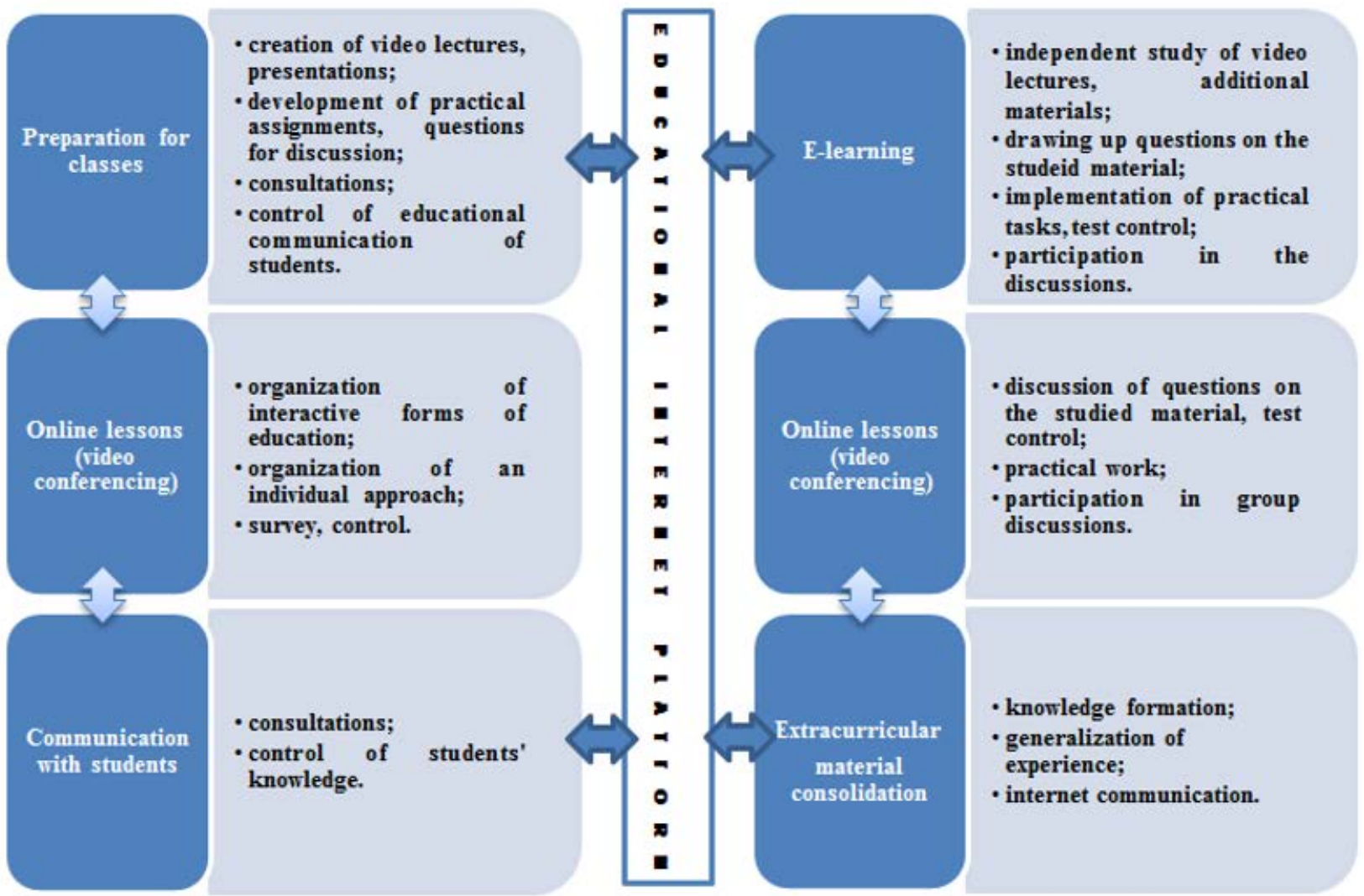

Figure 2. Methodological aspects of the Flipped Classroom technique.

Last academic year, we confirmed the effectiveness of this educational approach experimentally by introducing it as part of the digital educational resource implementation. It was found that working in the Flipped Classroom mode stimulates the development of the personal traits and characteristics of students (motivation, activity, volitional efforts), meta-subject skills (self-organization), as well as satisfaction with the organization of learning activity [12].

The Flipped Classroom model includes the design, organization and implementation of the educational process, in which the initial self-familiarization of students with new educational material is performed through work with online resources provided by the teacher (video lectures, video presentations and additional materials are used most often). Online resources are integrated into a digital educational resource on the Moodle platform, or into the created profile on the Microsoft Teams platform. The activities mediated by the "Virtual Classroom" module, which is part of the "Electronic University" information and analytical system of the Kazan Federal University, have also proven to be effective.

Video lectures and video presentations are developed by teachers independently using various programs and applications. Teachers can use vodcasts (lectures delivered by famous scientists). Jalinga STUDIO offers a wide range of technical options for preparing and filming video lectures. The recommended duration of video clips is $8-10 \mathrm{~min}$, and each educational video must be accompanied by clear educational goals and, if necessary, stepby-step instructions. It is advisable to use various types of educational material (illustrated slides combined with video, flash animations, audio, etc.).

Students make up questions for the studied educational material, prepare a short synopsis of the video lecture's content, and perform the proposed practical tasks, which are further tested as part of the practical classes or are included in the list of indepen- 
dent practical work; they also take part in online discussions via a chat and a forum in Microsoft Teams.

The following options are available for checking the acquisition of the educational material studied by the students. For example, this may include an online survey or a training test conducted prior to an online class or at the outset of the online practical lesson. An online test can be created using Microsoft Forms in the Assignment tab of the MS Teams. The teacher can both evaluate the test results and comment on mistakes and difficulties that students encountered. The automatic analysis of the group results allows one to get a true picture of the quality of the acquisition of the studied material. Another option for controlling knowledge acquisition is associated with the assessment of the quality of the practical task implementation offered in the video lectures.

The timely response of students to the proposed surveys and the ability to re-watch lectures helps students to clarify incomprehensible moments during the studying of the educational material.

Online classroom work is devoted to deepening and consolidating what has been learned through the discussion of the most important and complex issues, as well as the implementation of practical tasks directly under the guidance of a teacher and as part of the interaction with classmates.

During practical online classroom lessons, students participate in group discussions on key aspects of theoretical material and on the results of the completed practical tasks, as well as partaking in group work on problem assignments, in the analysis of specific situations and video cases, in role-playing and business games, in the development of educational and creative projects components, and so on. At the same time, each student has the right to freely express his or her standpoint in the search for optimal solutions to problems.

During online classes, it is necessary to take into account the attention patterns. There are peculiar periods of active attention equal to approximately 10-15 $\mathrm{min}$.

Taking into account the patterns of attention, it can be recommended, if necessary, to conduct mini-lectures as one of the more effective active forms of presenting theoretical material, wherein the lecturer alternates the theoretical material with regular intervals or breaks involving communication with students.

Let us consider the options for active intervals:

- A question from a lecturer, suggesting that students choose an answer, with students typing the answers in the chat of the MS Teams meeting;

- A challenge-question posed by the lecturer following the results of a mini-lecture, suggesting a short written answer, and students send the answers in the chat of the MS Teams meeting. Several answers are heard out loud through an "open microphone";

- Video vignettes involve showing mini-videos on the problem discussed in the minilecture, which can increase the interest of students and easily stimulate the concentration, critical thinking and personal reflections of students;

- Humor breaks can be used in the form of comic real or fictional stories thematically related to the problems of the mini-lectures;

- A puzzle break can be used in the form of a video quiz, focusing on a puzzle on the problem under study;

- A contest break, a small competition among students or between subgroups, suggesting immediate quick answers (2-3 questions).

After the online lesson, the further consolidation of the material is carried out by the students in the e-learning format (passing the test, performing independent semester work, participating in the discussion of the studied problem using chat and holding a forum in the team of the MS Teams, studying additional material, practicing peer-to-peer evaluation, etc.).

The peer-to-peer evaluation can be organized as follows: a teacher, using a specific Microsoft Teams Class Notebook, randomly assigns anonymous student's work and grading criteria to the Mutual Grade section of a specific student's Notebook. Each student should 
evaluate the work of their classmate. As a result, each student receives two marks: one for their own work and the other for the assessment of their fellow students' works.

Various approaches to the content organization of the educational process have been developed, taking into account the identified dominant motivators. Using a variety of active teaching methods, as well as a system of didactic means, facilitates the development of the procedural component of motivation, thanks to the development of students' cognitive and professional interests, the creation of a positive emotional environment during online classes (as a factor fostering the development of cognitive motives and motivation for achievement), and developing student activities in accordance with the individual characteristics of the educational process.

For example, one can use OneNote Class Notebooks to conduct simulated interactive lessons, which provide both a personal workspace for each student and a Collaboration Space for team collaboration through selected channels.

Group work was widely used in practical classes in order to increase communicative motives. The choice of the group composition depends on the tasks of the lesson. The following options are possible: working groups are formed to develop a thematic project; then, there is an exchange of developments with members of other groups, while each group must give both a critical assessment and identify the merits of developing the project of other participants. Another option is when the composition of the group is random, and the participants of the working groups perform the same problem tasks, which are evaluated on a competitive basis.

If the teacher plans to focus specifically on the individual motivation of students in the process of performing group work, then it is necessary to provide for control points (assessment milestones) in the process of work and to clearly define the assessment criteria.

Among the criteria, there may be the ability to work in a team (student's attitude to his or her work as a common or shared one; coordinated work together with others to achieve a common goal); mutual support along with consideration of each other; the ability to be critical of oneself; the evaluation of one's personal success or failure from the standpoint of the presented criteria.

When the teacher shifts the emphasis to collective motivation, it is necessary to competently approach the distribution of students into working groups. At the same time, the members of the selected groups are assigned a sequential number and they join the corresponding channels, so they can independently open meetings in their channels of the MS Teams team for group discussion.

If confidential work is required from the team members, then the teacher assigns the specific participants to the corresponding private channels of the MS Teams team.

Professional motivation plays an important role in teaching students, and this is the process of stimulating a person to learn new frontiers and areas of the profession and achieve professional success. When using distance learning technologies, it is more effective to increase this type of motivation as follows: demonstration of professional videos followed by discussion on forums (chats); watching broadcasts and recordings of lectures delivered by leading professors of universities around the world; the use of active teaching methods for the development of professional skills-for example, case studies; the use of training programs in various subjects (Coursera, Openedu, Eliademy, Universarium, etc.).

The main factor in the effectiveness of teaching and increasing motivation, including the motivation for creative self-realization, is the activity of students. We have previously noted various methods of organizing the active participation of students in online classes. It is essential to highlight the presentation of students' reports.

During the presentation, the students send questions for the presenter to the meeting chat, which he or she answers after the report is delivered. In turn, the speaker, highlighting the problem, organizes an interactive discussion with the audience on prepared questions, compiled crosswords, etc. When preparing a presentation report, various applications 
are used, including video editors for creating comic animations (Pixton Comics) and educational films (Inshot mobile application, etc.).

The social motives are developed thanks to the use of such techniques as: the method of competition; creating situations of success; praising; maintaining positive emotions; creating a situation of mutual assistance; search for contacts and cooperation; prompt insightful feedback; interest in the results of teamwork; open debriefing followed by encouragement.

It is relevant to consider some of the techniques used to increase motivation. For example, the organization of the competition as a method of education was carried out through the organization of a competition between teams in a quiz game. After independent study of the theoretical material, the following game can be organized: several teams are randomly selected, and within 10 min the teams must come up with 10 questions on the topic under study. The discussion takes place in several Microsoft Teams meetings hosted through the appropriate team channel. Further, the work is organized in the general channel of the team, and, in order of priority (regarding the circles), members of one team ask a question to the other. The team scores one point for a correct and complete answer. The time to formulate the answer is $1 \mathrm{~min}$. If a team gives an incomplete answer, then the other team has the right to complete the answer and receive an additional 0.5 points. For an incorrect answer, the right to offer an answer is given to the other team. The Microsoft OneNote application is used to keep track of the teams' answers. In the team captains' competition, quick answers are given only by the captains without any help of the teammates.

It is very important to create situations and conditions for the effective encouragement of students. One can praise students in different situations: if he or she takes an active part in the lesson/does an assignment; if the student asks questions, or is interested in the material; if they outline ways to improve the learning situation; if he or she has successfully achieved intermediate results, etc.

Learning motivation will increase if students realize that they themselves are in control of the situation, and that their success directly depends on the efforts made. Indeed, students should plan their own time and resources to finish the course modules on time.

Maintaining the positive emotions that arise in the learning process is of great importance. For this purpose, it is recommended to use various facts and examples that cause strong emotions, as well as bright visuals and emotionally rich, expressive speech on the part of the teacher.

Timely, constructive feedback helps maintain and increase students' motivation. Feedback should be informal, targeted and supportive. For example, when the teacher provides feedback on the work performed ("Feedback" section in the "Assignment" tab, opened in the General channel of the selected team), it is important to stress not only the shortcomings, but also the merits and strengths, of the student's work, as well as the achievements. Under these conditions, students, if necessary, will be ready to seek the necessary help from the teacher, and promptly respond to specific comments. It is also very effective to provide feedback via the Microsoft Teams chats.

Another important aspect is course evaluation. Trainees should know in advance the assessment criteria and the level of requirements for the course being studied. It will give them confidence in mastering the course, as well as the possibility of receiving additional bonuses for passing intermediate certification in fast-track and light modes. To increase the social significance of achievements, it is important to conduct an open debriefing that encourages them. Active students can be invited to participate in scientific conferences or forums at various levels.

\section{Discussion}

Abrupt and radical changes in the organization of the educational process at the university during the pandemic had a huge impact on all aspects of students' life. The process of adaptation to the conditions of distance learning does not occur by default; it is 
interconnected with the needs and motivations of an individual, and the attitude to the new conditions of the educational process.

As part of our study, we referred to the data and the implications contributed by other researchers (N.K. Bereznitskaya, O.A. Kondrashikhina (2021) [8], V.N. Panferov, S.A. Bezgodova, A.V. Miklyaeva (2020) [36], etc.) on the assessment of the educational situation by students, of their self-perception in the given educational situation, the quality of feedback from teachers, as well as the difficulties encountered.

At the same time, new interesting facts have been revealed. Most of the subjects during distance learning rated their general physical and mental state as average and good, while their own effectiveness was assessed lower in comparison with the traditional (offline) format of education.

More than $40 \%$ of students believe that distance learning can only partially replace offline education, while students have developed an understanding of distance learning's implications and a subjective perception of its significance. The transition to distance learning, according to junior students, will not negatively affect the quality of education. The choice of hybrid and blended learning formats was positively rated as effective in other studies [2].

In our study, it has been proposed to use various methods of effective organization of the educational process, and to search for alternative platforms and learning technologies among different options related to improving distance learning efficiency as factors to increase the educational motivation of students.

Difficulties and reductions in the quality of education during the transition to distance learning can be partially offset by promoting computer literacy, and developing competence in the distance learning technologies' application $[4,36,46]$.

The obtained results of our research partially confirm the previously published data on the leading educational motives of students, which include professional and cognitive motives [20-22].

In the context of distance education, communicative and social motives become the basis for the development of educational motivation [4,24].

It was found that many students tend to view the period of distance learning as an opportunity to expand their circle of communication and interaction, to acquire new acquaintances (data contradict the results of the study [4]), and to strengthen the focus on educational and professional activities and on the development of self-education and self-actualization, striving for more comprehensive exposure to and development of their abilities and their implementation, which is a creative approach to solving problems.

The activity of students as the foundation of the subject-activity motivation is based on the hope for success and the need to achieve success; the results obtained do not contradict the results of other scholars [19,39].

During the period of enforced distance learning, students were critical of themselves, they were not satisfied with their own behavior and level of achievements. Students were not able to adhere to the chosen behavioral pattern; they did not accept themselves in extreme situations, showing passivity, insufficient self-control, and dependence on external circumstances, evaluation and feedback (these results are confirmed in the research by V.N. Panferov et al. [36]).

It was found that, despite the students' awareness of the objective difficulties and advantages of the distance learning format, the subjective perception of the comfort and complexity of its implementation causes difficulties for junior students.

Students' motivation and involvement in the distance learning process could be effectively enhanced through the use of interactive forms of education (group discussions, analysis of specific situations and video cases, participation in role-playing and business games, development of elements of educational and creative projects, etc.; some of the proposed forms are substantiated in other studies [4]) and innovative pedagogical technologies (blended learning technology with the choice of the most effective Flipped Classroom model, gamification [55], project technology [54], etc.). 
The motivation of students increases, and their activity in the online environment grows, if interesting material is presented in an unusual and emotionally stimulating way, and with concise visualization [4].

In general, junior students are loyal to distance learning; the research results open up new opportunities for the development of psychological and pedagogical approaches in solving problems of optimizing the educational and cognitive activity of students, and increasing their motivation in the distance learning format, including under the conditions of emergency situations.

Along with the considered issues of motivating students' educational activities in the context of distance learning, new problems appear, associated with the further identification and testing of other innovative technologies in the organization of hybrid and mobile learning, as well as with organizational, methodological, psychological and pedagogical support for the development of educational motivation.

Learning motivation will increase if students realize that they themselves are in control of the situation, that their success directly depends on the efforts made, and if the conditions are created for the meaningful acquisition of the educational material by students, i.e., endowing the information perceived with a personal meaning as one of the important factors of training effectiveness, determining the purpose and significance of studying the material.

It is shown that through specially organized rating activity, it is possible to consolidate educational motives that are conscientiously aligned with the content of the program material, as well as with the requirements of the professional focus of education.

It is known that an important component of distance learning is the connection between the subjects of the educational process. With the accumulation of online learning experience, students showcase a significant increase in academic engagement against the background of a pronounced reduction in the quality of the feedback from teachers [2,36].

To effectively address educational problems in distance learning and increase the subject-activity motivation of students, it is relevant to create virtual learning communities (for example, using social networks) and group forums on educational internet platforms, and to organize conditions for the development of an emotionally trusting and respectful attitude of teachers to students.

\section{Conclusions}

Given the exceptional situation, social tension and existing risks, the effectiveness of distance learning in a pandemic is largely attributable to the psychological readiness, motivation and organization of students and teachers.

The main reasons for the decline in students' motivation to learn under the new conditions of online learning are technical problems, the problems of understanding and perceiving information, and problems of self-organization. Motives represent a dynamic system, so they can be strengthened, weakened, and even changed in the learning process, taking into account the hierarchy and dynamics of their change in the learning process.

Awareness of the new opportunities and technological limitations of higher education, arising from the analysis of this challenging period, should make it possible to take a new step towards increasing the competitiveness of higher education in Russia.

Our research has a number of limitations. The limited number of participants does not allow us to generalize the results to a broader context, but our study could form the basis for future research. The study opened up interesting perspectives regarding approaches to the content management of the educational process in a distance format, with various ways and techniques of increasing the educational motivation of students under the conditions of distance learning. However, this study is only the beginning, and future in-depth research is required, especially regarding various factors impacting the students motivation for learning in post-pandemic times. Second, similar studies could be conducted across different higher education settings and with different members of the higher school community, such as department heads. The effect of different stimuli on students is still 
an underrepresented field and would benefit from further research. Future research with different and larger samples of students, for instance by designing a questionnaire, could further investigate the influence of the background of the students, such as age, gender and type of education, on the emergence and character of the tensions. Finally, it would be valuable to conduct international studies to investigate whether students from different cultures have different views regarding their motivation for learning.

Author Contributions: Conceptualization, R.A.V.; methodology, A.R.D.-Z.; formal analysis, R.A.V.; investigation, A.R.D.-Z.; writing — original draft preparation, A.R.D.-Z. and N.R.L.; writing-review and editing, R.A.V. and N.R.L. All authors have read and agreed to the published version of the manuscript.

Funding: This research received no external funding.

Institutional Review Board Statement: The study was conducted according to the guidelines of the Declaration of Helsinki, and approved by the Institutional Review Board (or Ethics Committee) of the Institute of Psychology and Education, Kazan federal university (protocol code 7 and date of approval-30 April 2020).

Informed Consent Statement: Informed consent was obtained from all subjects involved in the study.

Acknowledgments: This paper has been supported by the Kazan Federal University Strategic Academic Leadership Program.

Conflicts of Interest: The authors declare no conflict of interest.

\section{References}

1. Terentyeva, E.R. Educational motivation of students during the pandemic. In Proceedings of the Regional Research and Practice Conference-Health Psychology in the Educational Process, Kursk, Russia, 25 September 2020; KSMU: Kursk, Russia, 2020; pp. 108-111.

2. Maryin, M.I.; Nikiforova, E.A. Transformation of Motives and Values of Students of Higher Educational Institutions in Context of the Pandemic (foreign research case). Sovrem. Zarubezhnaya Psikhologiya-Mod. Foreign Psychol. 2021, 10, 92-101. [CrossRef]

3. Jones, A.; Issroff, K. Learning Technologies: Affective and Social Issues in Computer-supported Collaborative Learning. Comput. Educ. 2005, 44, 395-408. [CrossRef]

4. Struchkova, Y.V.; Koryakina, T.G. Problem of the Development of Educational Motivation of the Freshmen in the Context of Distance Learning. Sovrem. Nauk. Tekhnologii-Mod. High Technol. 2021, 5, 215-220. [CrossRef]

5. Kononykhina, O.V. Motivating Students in Distance Learning. Mezhdunarodnyy Zhurnal Gumanit. I Yestestvennykh Nauk.-Int. J. Humanit. Nat. Sci. 2021, 2-1, 107-111. [CrossRef]

6. Baber, H. Determinants of Students' Perceived Learning Outcome and Satisfaction in Online Learning during the Pandemic of COVID19. J. Educ. E-Learn. Res. 2020, 7, 285-292. [CrossRef]

7. Chen, P.-S.D.; Lambert, A.D.; Guidry, K.R. Engaging online learners: The impact of web-based learning technology on college student engagement. Comput. Educ. 2010, 54, 1222-1232. [CrossRef]

8. Bereznitskaya, N.K.; Kondrasikhina, O.A. Attitude of Psychology Students to Distance Learning during the COVID-19 Pandemic. Mod. Sci. 2021, 5-1, 393-399.

9. Golovina, I.V.; Alexandrova, T.Y. Distance Learning: The Problem of Motivation. Nauka I Obraz. Khozyaystvo I Ekon. Predprin. Pravo I Upr.-Sci. Educ. Econ. Econ. Entrep. Law Gov. 2021, 5, 22-26.

10. Medvedeva, N.A.; Musikhina, L.V. Formation of Students' Motivation to Master Information Technologies during the Pandemic. Int. Sci. Rev. 2020, LXXI, 90-92. Available online: https://cyberleninka.ru/article/n/formirovanie-motivatsii-studentov-kosvoeniyu- (accessed on 10 September 2021).

11. Tantsura, T.A. The Problem of Motivating Students to Learn a Foreign Language during the Transition to a Distance Learning Format. Mir Nauk. Kult. Obraz.-World Sci. Cult. Educ. 2020, 3, 281-282. [CrossRef]

12. Fedorova, M.A. Formation of Educational Independent Activity of Students: Textbook for Universities; Uraight Publishing House: Moscow, Russia, 2020.

13. Tsarapkina, Y.M.; Mironov, A.G.; Kireicheva, A.M. Potential of Application and Prospects for the Development of Distance Learning. Sovrem. Issled. Sotsialnykh Probl.-Mod. Stud. Soc. Probl. 2017, 8, 304-318. [CrossRef]

14. Ince, E.Y. Distance Education in Higher Education in the COVID-19 Pandemic Process: A Case of Isparta Applied Sciences University. Int. J. Technol. Educ. Sci. 2020, 4, 343-351. [CrossRef]

15. Kondrasikhina, O.A.; Medvedeva, S.A. Education of the Future: Harmonizing the Implementation of MOOCs in the Universities. In Proceedings of the 2nd International Research and Practice Conference-Working with the Future in the Context of Lifelong Education, Moscow, Russia, 18-19 April 2019; Moscow City Pedagogical University, “A-Prior”: Moscow, Russia, 2019; pp. 3-11. 
16. Kalatskaya, N.N.; Kostyunina, N.Y.; Drozdikova-Zaripova, A.R. Motivational Peculiarities of Schoolteachers in Russia. Life Sci. J. 2014, 11, 243-247. Available online: https://lifesciencesite.com/lsj/life1111s/055_25830life1111s14_243_247.pdf (accessed on 10 September 2021).

17. Medvedeva, I.A. The Relationship between the Motives of Entering the University and the Satisfaction with the Chosen Profession of Students Training at Various Educational Institutions. Ph.D. Thesis, Penza State Pedagogical University Named after V.G. Belinsky, Penza, Russia, 2003.

18. Melanthiou, Y.; Thrassou, A.; Vrontis, D. A value-based transcription of student choices into higher education branding practices. Glob. Bus. Econ. Rev. 2017, 19, 121-126. [CrossRef]

19. Rogov, M.G. Motivation of Educational and Commercial Activities of Students. Vyss. Obraz. V Ross.-High. Educ. Russ. 1998, 4, 90-96.

20. Rakhmatullina, F.M. Motivational basis of Educational and Cognitive Activity of a Person. In Psychological Service in the University; Peisakhov, N.M., Ed.; Publishing House of Kazan University: Kazan, Russia, 1981; pp. 90-104.

21. Chirkina, S.E. Motives of the Educational Activity of a Modern Student. Educ. Self-Dev. 2013, 4, 83-89.

22. Zhdanova, S.Y. The Style of Educational Activity and Its Development (Based on the Study of Students-Philologists and Mathematicians). Ph.D. Thesis, Perm State Pedagogical University, Perm, Russia, 1997.

23. Afanasenkova, E.L. Learning Motives and their Change in the Process of Teaching University Students. Ph.D. Thesis, Moscow Psychological and Social Institute, Moscow, Russia, 2005.

24. Drozdikova-Zaripova, A.R.; Kalatskaya, N.N.; Kostyunina, N.Y. The research of educational motivation of working and nonworking Russian students. Rev. Eur. Stud. 2015, 7, 108-117. [CrossRef]

25. Tenkova, V.A. Features of Educational Motivation of Students. Vestn. Voronezhskogo Gos. Univ.-Voronezh State Univ. Bull. 2015, 4, 87-90.

26. Keller, J.M. Motivational Design for Learning and Performance: The ARCS Model Approach; Springer: New York, NY, USA, 2010.

27. Sokolskaya, N.V. Motivation Specificity of University Students Educational Activity as part of Distance Learning Technology (Case of Foreign Language Studying). Ph.D. Thesis, Kursk State University, Kursk, Russia, 2006.

28. Afanasyeva, A.S. Content and Specificity of Motivation of Educational Activity of Distance Learning Students. Ph.D. Thesis, PG Demidov Yaroslavl State University, Yaroslavl, Russia, 2018.

29. Morat, B.N.; Shaari, A.; Abidin, M.J.Z. Facilitating ESL Learning Using Youtube: Learners' Motivational Experiences; Association of Malaysian Researchers, Social Services Faculty of Teacher Training and Education, Universitas Syiah Kuala, Darussalam: Banda Aceh, Malaysia, 2016.

30. Melor, M.Y.; Salehi, H.; Chenzi, C. Integrating social networking tools into ESL writing classroom: Strengths and weaknesses. Engl. Lang. Teach. 2019, 5, 42-48. [CrossRef]

31. Hsu, H.-C.K.; Wang, C.V.; Levesque-Bristol, C. Reexamining the impact of self-determination theory on learning outcomes in the online learning environment. Educ. Inf. Technol. 2019, 24, 2159-2174. [CrossRef]

32. Johnson, E.; Morwane, R.; Dada, S.; Pretorius, G.; Lotriet, M. Adult Learners' Perspectives on Their Engagement in a Hybrid Learning Postgraduate Programme. J. Contin. High. Educ. 2018, 66, 88-105. [CrossRef]

33. Luna, M.E.O.; Cruz, C.S.L.; Arce, J.O. Achievement, Engagement and Student Satisfaction in a Synchronous Online Course. In Proceedings of the 2019 IEEE Global Engineering Education Conference (EDUCON), Dubai, UAE, 8-11 April 2019 ; pp. 124-132.

34. Grigoryan, N.A.; Kolmakova, T.S.; Galustyan, L.K. The degree of anxiety growth of distance learners in the first year of Rostov State Medical University in connection with the pandemic of a new coronavirus infection. Probl. Sovrem. Obraz.-Probl. Mod. Educ. 2020, 5, 31-37. [CrossRef]

35. Kryzhanovskaya, Y.A. Distance education in the context of restrictive measures and its impact on the readiness of students for this format of classes. Sovrem. Inf. Tekhnologii I IT-Obraz.-Mod. Inf. Technol. IT Educ. 2020, 16, 482-489. [CrossRef]

36. Panferov, V.N.; Bezgodova, S.A.; Miklyaeva, A.V. Dynamics of students' attitudes towards distance learning (results of a longitudinal study). In Proceedings of the International Scientific and Practical Online Conference-Personal and Regulatory Resources for Achieving Educational and Professional Goals in the Era of Digitalization, Online, 22-23 October 2020; Znanie-M: Moscow, Russia, 2020; pp. 204-217.

37. Isakova, A.I.; Levin, S.M. Models of Increasing Student Motivation in the Educational Process of the University. Inzhenernoye Obraz.-Eng. Educ. 2020, 28, 20-30. Available online: http://aeer.ru/files/io/m28/art_3.pdf (accessed on 10 September 2021).

38. Kitova, E.B.; Troshkin, M.I. Academic Motivation and the Impact of Distance Learning During Lockdown: University Students' Perspective. Izv. Baikalskogo Gos. Univ.-Bull. Baikal State Univ. 2020, 30, 341-350. [CrossRef]

39. Händel, M.; Bedenlier, S.; Glaser-Zikuda, M.; Kammerl, R.; Kopp, B.; Ziegler, B. Do Students have the Means to Learn during the Coronavirus Pandemic Student Demands for Distance Learning in a Suddenly Digital Landscape. PsyArXiv 2020, 27, Preprint. [CrossRef]

40. Williams, S.N.; Armitage, C.J.; Tampe, T.; Dienes, K. Public perceptions and experiences of social distancing and social isolation during the COVID-19 pandemic: A UK-based focus group study. BMJ Open 2020, 10, 8. [CrossRef] [PubMed]

41. Dickey, M. The impact of web-logs (blogs) on student perceptions of isolation and alienation in a web-based distance-learning environment. Open Learn. 2004, 19, 279-291. [CrossRef] 
42. Owens, J.; Hardcastle, L.; Richardson, B. Learning from a Distance: The Experience of Remote Students. J. Distance Educ. 2009, 23, 53-74. Available online: File:/ / C:/Users/valey/Downloads/Learning_from_a_distance_The_experience_of_remote_.pdf (accessed on 10 September 2021).

43. Lovrić, R.; Farčić, N.; Mikšić, Š.; Včev, A. Studying During the COVID-19 Pandemic: A Qualitative Inductive Content Analysis of Nursing Students' Perceptions and Experiences. Educ. Sci. 2020, 10, 188. [CrossRef]

44. Chang, Y.H.; Lin, P.R.; Lu, Y.T. Development of a Kinect-Based English Learning System Based on Integrating the ARCS Model with Situated Learning. Sustainability 2020, 12, 2037. [CrossRef]

45. Wahyudi, S. Learning Model of Attention, Relevance, Confidence, Satisfaction (ARCS) Supported by Video Tutorial to Improve the Students' Learning Motivation in Vocational High School. Adv. Soc. Sci. Educ. Humanit. Res. (ASSEHR) 2017, 158, 603-611. [CrossRef]

46. Alenezi, A.M. The relationship of students' emotional intelligence and the level of their readiness for online education: A contextual study on the example of university training in Saudi Arabia. Obraz. I Nauka-Educ. Sci. J. 2020, 22, 89-109. [CrossRef]

47. Rafique, G.M.; Mahmood, K.; Warraich, N.F.; Rehman, S.U. Readiness for Online Learning during COVID-19 pandemic: A survey of Pakistani LIS students. J. Acad. Librariansh. 2021, 47, 102346. [CrossRef]

48. Pardanjac, M.; Karuovic, D.; Eleven, E. Increase of user motivation in teaching realized through distance learning. DAAAM Int. Sci. Book 2017, 10, 131-144. [CrossRef]

49. Blokhovtsova, G.G.; Malikova, T.L.; Simonenko, A.A. Prospects for the development of distance learning. Novaya Nauka: Strateg. I Vektory Razvit.-New Sci. Strateg. Dev. Vectors 2016, 118, 89-92.

50. Bazaliy, R.V. Development of student motivation in the context of distance learning. Mir Nauki. Pedagog. I PsikhologiyaWorld Sci. Pedagog. Psychol. 2020, 8, 23-28. Available online: https://mir-nauki.com/PDF/03PDMN320.pdf (accessed on 10 September 2021).

51. Elkina, I.Y. On the Issue of Increasing the Educational Motivation of Distance Learning Students. Obraz. Resur. I Tekhnologii-Educ. Resour. Technol. 2020, 1, 43-48. [CrossRef]

52. Babaeva, LL Innovative technologies of distance education. Nauka Tekhnika I Obraz.-Sci. Technol. Educ. 2020, 5, 77-80.

53. Drozdikova-Zaripova, A.R.; Sabirova, E.G. Usage of Digital Educational Resources in Teaching Students with Application of 'Flipped Classroom' Technology. Contemp. Educ. Technol. 2020, 12, 1-13. [CrossRef]

54. Baryshnikova, E.V. Development of Professional Motivation of Future Educational Psychologists in the Context of Distance Learning with the Use of Innovative Technologies. Uchenyye Zap. Univ. Im. P.F. Lesgafta-Sci. Pap. P.F. Lesgaft Univ. 2020, 8, 335-340. [CrossRef]

55. Afonasova, M.A. Instruments for Motivating and Maintaining Students' Activity in the Electronic Educational Environment. In Proceedings of the International Scientific and Methodological Conference-Modern education: Increasing the Competitiveness of Universities, Tomsk, Russia, 28-29 January 2021; Tomsk State University of Control Systems and Radioelectronics: Tomsk, Russia, 2021; pp. 172-175. 